\title{
Terrestrial species adapted to sea dispersal: Differences in propagule dispersal of two Caribbean mangroves
}

\author{
Richard G. J. Hodel $^{1,2,3}$ (D) | L. Lacey Knowles ${ }^{3}$ | Stuart F. McDaniel ${ }^{1,4}$ | \\ Adam C. Payton ${ }^{1}$ | Jordan F. Dunaway ${ }^{1}$ | Pamela S. Soltis ${ }^{2,4,5}$ | Douglas E. Soltis ${ }^{1,2,4,5}$
}

\author{
${ }^{1}$ Department of Biology, University of \\ Florida, Gainesville, Florida \\ ${ }^{2}$ Florida Museum of Natural History, \\ University of Florida, Gainesville, Florida \\ ${ }^{3}$ Department of Ecology and Evolutionary \\ Biology, University of Michigan, Ann Arbor, \\ Michigan \\ ${ }^{4}$ The Genetics Institute, University of \\ Florida, Gainesville, Florida \\ ${ }^{5}$ The Biodiversity Institute, University of \\ Florida, Gainesville, Florida

\section{Correspondence} \\ Richard G. J. Hodel, Department of Biology, \\ University of Florida, Gainesville, FL. \\ Email: richiehodel@gmail.com
}

\begin{abstract}
A central goal of comparative phylogeography is to understand how species-specific traits interact with geomorphological history to govern the geographic distribution of genetic variation within species. One key biotic trait with an immense impact on the spatial patterns of intraspecific genetic differentiation is dispersal. Here, we quantify how species-specific traits directly related to dispersal affect genetic variation in terrestrial organisms with adaptations for dispersal by sea, not land-the mangroves of the Caribbean. We investigate the phylogeography of white mangroves (Laguncularia racemosa, Combretaceae) and red mangroves (Rhizophora mangle, Rhizophoraceae) using chloroplast genomes and nuclear markers (thousands of RADSeq loci) from individuals throughout the Caribbean. Both coastal tree species have viviparous propagules that can float in salt water for months, meaning they are capable of dispersing long distances. Spatially explicit tests of the role of ocean currents on patterning genetic diversity revealed that ocean currents act as a mechanism for facilitating dispersal, but other means of moving genetic material are also important. We measured pollen- vs. propagule-mediated gene flow and discovered that in white mangroves, seeds were more important for promoting genetic connectivity between populations, but in red mangroves, the opposite was true: pollen contributed more. This result challenges our concept of the importance of both proximity to ocean currents for moving mangrove seeds and the extent of long-distance pollen dispersal. This study also highlights the importance of spatially explicit quantification of both abiotic (ocean currents) and biotic (dispersal) factors contributing to gene flow to understand fully the phylogeographic histories of species.
\end{abstract}

KEYWORDS

Caribbean, comparative phylogeography, long-distance dispersal, mangroves, RAD-Seq

\section{1 | INTRODUCTION}

In many terrestrial taxa with populations separated by water (e.g., island systems), dispersal is typically constrained by the lack of an intrinsic mechanism of overwater dispersal. In contrast, in some

P.S.S. and D.E.S. are cosenior authors. species adapted to coastal habitats, dispersal by sea, not land, predominates (Kinlan \& Gaines, 2003), as in many marine animal species where ocean currents facilitate larval dispersal (Galindo, Olson, \& Palumbi, 2006; Nathan et al., 2008). For example, unlike most tree species, sea dispersal via propagules characterizes different mangrove taxa, which live exclusively at the interface of the marine environment and coastlines. While ocean currents clearly are an 
important abiotic factor influencing genetic patterns in some mangrove species (Gillespie et al., 2011), biotic properties of the propagules of species also differ, raising the prospect that species-specific traits, like those studied in their terrestrial plant counterparts (e.g., Massatti \& Knowles, 2016), could also be important in shaping the degree to which coastal communities exhibit similar genetic patterns. Here, we explore the relative roles of abiotic and biotic factors with a comparative analysis of two Caribbean coastal angiosperms, red mangroves (Rhizophora mangle, Rhizophoraceae) and white mangroves (Laguncularia racemosa, Combretaceae).

Research in several subdisciplines of biology has shown that dispersal is a powerful force that can shape both the distributions of species and patterns of genetic structure within species. Early empirical tests of island biogeography, such as Simberloff and Wilson's (1969) classic fumigation experiments, showed that islands closer to continents were colonized more quickly than distant islands, highlighting the need to understand island colonization mechanisms. Historically, dispersal was not considered interesting and/or relevant to biogeographic studies-interpreted as little more than stochastic noise-and vicariance was the mechanism that drove biogeographic patterns (reviewed in Humphries \& Parenti, 1999). More recently, the biogeographic research community has better acknowledged the importance of dispersal in determining species distributions (de Queiroz, 2005). Subsequent research found that abiotic factors (e.g., environmental barriers or environmental facilitation of colonization) and biotic factors (i.e., dispersal) are both important aspects of colonization (Gillespie et al., 2011; Losos \& Schluter, 2000). Early phylogeographic studies accounted for the role of dispersal to a much greater extent than biogeographic studies (e.g., Avise, Alisauskas, Nelson, \& Ankney, 1992; Burban \& Petit, 2003). Nevertheless, a polarized view of vicariance and dispersal has continued into comparative phylogeographic studies (Papadopoulou \& Knowles, 2016), in which a lack of phylogeographic concordance was considered to result from species-specific differences in dispersal, and therefore uninteresting and unimportant. As the body of comparative phylogeography literature has grown to include a wide range of organisms and greater amounts of genomic data, a more nuanced view of the vicariance-dispersal continuum has emerged-one that explicitly addresses species-specific biotic factors as well as abiotic ones, and that recognizes the importance of dispersal in shaping genetic structure within species.

Red and white mangroves are largely codistributed in neotropical coastal estuarine habitats, and both disperse via viviparous (i.e., germinated) seedlings that abscise from the parent plant and float for months in the ocean before potentially finding suitable substrate (Allen \& Krauss, 2006; Rabinowitz, 1978; Tomlinson, 2016). Both species produce a large number of seeds, at a substantial cost to the parent plant (Tomlinson, 2016), but red mangroves have larger and longer-living seedlings, and live closer to the water, than do white mangroves. Thus, we predict that red mangroves will exhibit greater connectivity between populations through seeds than white mangroves, with relatively little difference between the two species in pollen-based estimates of gene flow, because even though the two species have different pollination syndromes (i.e., wind vs. insect), this difference is relatively small compared to the differences in propagule traits between the species. Furthermore, we predict that the patterns of genetic differentiation will reflect differences in the degree of isolation among populations as a function of the geographic distance separating populations, augmented by oceanic currents (i.e., the seascape; Galindo et al., 2006). We characterize the phylogeographic structure of red and white mangroves using both nuclear (RAD-Seq loci) and chloroplast (chloroplast genome sequences) loci from sampling locations across the Caribbean to tease apart how differences in dispersal in these two species affect the observed phylogeographic patterns.

Moreover, we apply analyses, which in addition to quantifying the association between genes and geography, also provide a framework for assessing departures from isolation-by-distance (IBD) patterns. This includes both quantifications of statistical deviations, which when considered in the light of the geographic distribution of populations in a spatially explicit framework, can identify general trends that might correspond with impediments from currents, as well as identification of how abiotic factors influence genetic variation. We investigate the effect of two abiotic factors, land type (island or continent) and island size, on the degree to which the genetics of a population deviated from the null expectation (i.e., IBD). The impact of land type (island vs. continental) and island size on factors important for biogeographic patterns (e.g., speciation rate) has been investigated in biogeographic studies (e.g., Losos \& Ricklefs, 2009), but spatially explicit phylogeographic investigation is needed in systems with both island and continental distributions, where abiotic and/or biotic factors may influence movement of genetic material between the two.

Not only does this study add to a growing body of work on species-specific vs. assemblage-wide patterns of genetic variation (e.g., Carnaval, Hickerson, Haddad, Rodrigues, \& Moritz, 2009; Oliveira et al., 2018; Papadopoulou \& Knowles, 2016; ResendeMoreira et al., 2018), but it also expands such research to terrestrial taxa whose dispersal mode differs from most studies to dateterrestrial coastal taxa adapted to oceanic dispersal. For many taxa, the only way that genetic material will exchange between islands is through rare events. These events include slow, long-distance successful rafting that occurs with low probability, infrequent birdmediated transport, and rare storms or hurricanes that can quickly transport genetic material long distances (Gillespie et al., 2011). We explore the rarity of long-distance dispersal (LDD) in species with continental and island distributions and how the relative frequency of LDD events affects genetic patterns. Many methodologies used in this study, particularly the spatially explicit quantification of abiotic factors that influence dispersal between populations, will be widely applicable to future research in other diverse taxa, including additional plants, as well as mammals, reptiles and insects in oceanic island systems (e.g., Heaney, Walsh, \& Townsend Peterson, 2005; Juan, Emerson, Oromí, \& Hewitt, 2000). Our analyses are also applicable to some terrestrial systems (e.g., some terrestrial systemssky islands-have many similarities to oceanic island systems; Moore 
et al., 2013; Salerno, Señaris, Rojas-Runjaic, \& Cannatella, 2015). Finally, populations in many other terrestrial systems in diverse taxa can be viewed as islands when an environmental feature limits genetic interchange between populations. Quantifying the abiotic factor(s) that isolate populations in a spatially explicit context will allow for more powerful analyses of how these factors interact with biotic factors to shape phylogeographic patterns (Riginos, Crandall, Liggins, Bongaerts, \& Treml, 2016).

\section{2 | MATERIALS AND METHODS}

\section{1 | Sample collection and DNA isolation}

We collected leaf tissue from mature plants of each species from sampling locations in North America, Central America, South America and Caribbean Islands (Supporting Information Table S1). Vouchers were deposited in the University of Florida herbarium (FLAS) at the Florida Museum of Natural History (accession numbers: FLAS 267604, 267605, 267607, 267608, 267610-267612, $267614,267615,267617-267619)$. These two species are codistributed throughout coastlines in the neotropics; in total, we sampled 28 populations of red mangroves and 20 populations of white mangroves. At each location, we collected one leaf from 1 to 16 individuals that were spaced at least $15 \mathrm{~m}$ apart to minimize collecting closely related individuals. Herbarium specimens from the New York Botanical Garden (NYBG) were used in cases for sampling locations that were difficult or prohibitively expensive to reach. GPS coordinates for each sampling location were recorded. For each sampling location, we used between one and eight individuals in genetic analyses; in locations where herbarium specimens were used, we were often limited to one individual per location. In locations where more than eight individuals were sampled, we randomly selected eight individuals for use in genetic analyses. Each sampled leaf was placed in a labelled bag with silica gel and stored for $1-12$ months at $4{ }^{\circ} \mathrm{C}$; we then extracted DNA from the dried leaf tissue using a standard CTAB protocol (Doyle \& Doyle, 1987).

\section{2 | RAD-Seq library preparation and data processing}

We followed the double-digest RAD-Seq protocol of Peterson, Weber, Kay, Fisher, and Hoekstra (2012). We constructed DNA libraries for each sample by digesting approximately $200 \mathrm{ng}$ genomic DNA with EcoRI and Msel and then ligating Illumina adapters and unique 8-, 9-, 10- and 14-nucleotide barcodes to the DNA fragments. The DNA libraries were PCR-amplified in 22 separate reactions and pooled to minimize early PCR bias. We size-selected 250- to 450-bp fragments using a PIPPIN ELF gel and sequenced the DNA fragments using the $1 \times 100$-bp setting on the Illumina HiSeq 4000 platform at the University of Florida Interdisciplinary Center for Biotechnology Research (ICBR). Raw sequence data were deposited in the NCBI Sequence Read Archive (SRA; accession numbers SRR7501584SRR7501638; SRR7504176-SRR7504186). We processed the raw
Illumina reads using the iPyrad pipeline (Eaton, 2014; http://ipyrad. readthedocs.io/). We used iPyrad to perform all necessary steps for processing RAD-Seq data (sorting, filtering, clustering, consensus, clustering, formatting). As all barcodes differed by at least two nucleotides, we demultiplexed the loci, allowing one mismatch in the barcode and using the most stringent filtering of Illumina adapters.

The loci were assembled using a de novo approach with the following cut sites: CAATTC, ATT. We added a C before the EcoRI cut site (AATTC became CAATTC) because our double-digest RAD-Seq protocol adds a "protector base" to prevent any undigested restriction enzymes from cleaving off recently incorporated adapters after the ligation step. For all other assembly parameters, we used the iPyrad defaults. We then filtered the loci for human, fungal and microbial contamination and filtered loci by representation across individuals using an R script (Data_Filtering.R; this script and all other scripts are available at https://github.com/richiehodel/ Caribbean_mangroves). We used minimal filtering of loci to avoid excluding informative loci, as both in silico and empirical studies indicate that high amounts of missing data do not negatively impact RAD-Seq data sets (Hodel et al., 2017; Huang \& Knowles, 2016).

We obtained an average of 3,991,640 reads (minimum: 70,631, maximum: 18,253,041) for red mangrove individuals in the RADSeq analysis. The final red mangrove nuclear data set consisted of an average of 28,929 RAD-Seq loci across 122 individuals (average 19,219; minimum 426; maximum 27,978). The white mangrove reads consisted of an average of 1,446,498, minimum of 119,681 and maximum of 7,267,782. The white mangrove nuclear data set had 29,767 loci (average 14,253; minimum 360; maximum 28,799) RAD-Seq loci for 54 individuals.

\section{3 | Chloroplast genome sequencing and assembly}

We selected 50 individuals of each species for complete chloroplast genome sequencing using a random-shearing genome skimming approach (Steele et al., 2012; Straub et al., 2011). The individuals were selected to provide wide coverage of the sampling locations; 1-3 individuals per species per sampling location were used in chloroplast genome sequencing. DNA libraries were constructed by RAPiD Genomics (Gainesville, FL, USA) and sequenced at the UF ICBR using a HiSeq 4000 with $2 \times 100$ bp reads. Raw reads were de novo assembled into contigs using Velvet (Zerbino \& Birney, 2008) with Kmer lengths ranging from 31 to 81 . The contigs were then mapped to a reference chloroplast genome of Oenothera villaricae (NCBI accession number NC_030532.1) for white mangroves and Populus alba (NCBI accession number AP008956.1) for red mangroves, using BOWTIE2 (Langmead \& Salzberg, 2012), as implemented in Geneious (Kearse et al., 2012). These taxa were selected as references because they were the most closely related species that had publicly available chloroplast genome sequences. Raw reads and assembled chloroplast genomes were deposited in the NCBI Sequence Read Archive database (accession numbers SRR7779779-SRR7779767; SRR7781534-SRR7781581). The red mangrove chloroplast genome alignment (50 individuals) was $130,120 \mathrm{bp}$, and the overall pairwise 
sequence identity was $99.6 \%$. The average GC content was $36.2 \%$, and on average, there were $15,707 \mathrm{bp}$ of ambiguous sites per individual. The white mangrove chloroplast alignment also consisted of 50 individuals and was $135,357 \mathrm{bp}$ in length. There was $99.4 \%$ pairwise sequence identity overall, and on average, there were 48,930 ambiguous sites per individual.

\section{4 | Phylogeographic analyses}

Phylogeographic analyses were performed on both the nuclear (RAD-Seq) and chloroplast genome data separately for each species. To assess phylogeographic patterns within each species, we calculated pairwise average $F_{\mathrm{ST}}$ using an R script (Pairwise_Fst.R) and the r packages "Hierfstat" (Goudet, 2005) and "popgenome" (Pfeifer, Wittelsbürger, Ramos-Onsins, \& Lercher, 2014). Pairwise $F_{S T}$ is a valuable metric for assessing how historical factors and ongoing gene flow influence structure between populations. In these two species, historical factors (e.g., isolation between distant populations) and/or ongoing gene flow (e.g., via dispersal, pollen flow and colonization) could impact pairwise $F_{\mathrm{ST}}$.

\section{5 | Phylogenetic analyses with SVDQUARTETS and RAXML}

To determine genealogical relationships among individuals within species, we used coalescent analyses in sVDquartets (Chifman \& Kubatko, 2014). This program selects the optimal topology for a quartet of taxa, and, after sampling millions of quartets, infers a phylogeny for all individuals based on choosing the quartets with the best scores and assembling them into a phylogenetic tree. For each RAD data set, we evaluated all possible quartets and selected trees under the multispecies coalescent using QFM (Quartet Fiduccia Mattheyses) quartet assembly (Reaz, Bayzid, \& Rahman, 2014). We used nonparametric bootstrapping (100 replicates for each data set) to assess confidence in inferred genealogical relationships between individuals. The $\mathrm{R}$ script Tree_Formatting. $\mathrm{R}$ was used to visualize and annotate the $50 \%$ majority-rule trees from SVDQUARTETS using the r packages "APE" (Paradis, Claude, \& Strimmer, 2004) and "GGTREE" (Yu, Smith, Zhu, Guan, \& Lam, 2017). For comparative purposes, we also used RAXML (Stamatakis, 2014) to infer the phylogenetic relationships between individuals of both species using the RAD-Seq data. RAXML was used to infer phylogenetic relationships between chloroplast genomes for each individual in each species. In all RAXML analyses, we employed the GTRGAMMA model of evolution and ran 100 bootstrap replicates.

\section{6 | Isolation-by-distance tests and Procrustes analysis}

As geographic distance is often a key component in spatial patterns of genetic diversity, we conducted Mantel tests to test for IBD by comparing matrices of geographic and genetic distances with the R package "VEGAN" (Oksanen et al., 2017) and a custom script
(Mantel_Procrustes.R). A principal component analysis (PCA) implemented in the R package "SNPRELATE" (Zheng et al., 2012) identified clusters of individuals, using RAD data and chloroplast data separately in each species (see R script VCF_PCA.R). To further investigate the relationship between genes and geography, we implemented a Procrustes analysis, which finds an optimal transformation that maximizes the similarity between genetic variation in PCA space and sample locations in geographic space (Wang et al., 2010). For each species, the Procrustes analysis compared two matrices: one with the latitude and longitude of each sampling location, and one with principal components one and two, as calculated using the $\mathrm{R}$ packages "GDSFMt" and "SNPRELATE" using the script VCF_PCA.R. The Procrustes analysis not only quantifies the strength of the association between genetic and geographic variation, but also shows the amount of genetic deviance of individuals from their expected genetic position based on where they were sampled geographically. As the Procrustes analysis identifies the optimal transformation (i.e., rotation of matrices) that maximizes the similarity between genetic principal components and geographical coordinates of sampling locations, the arrows represent the degree of deviation from a signature of IBD. The direction of the arrows shows in two dimensions the strength of the deviation (e.g., how a population may genetically look much more like a neighbouring population to the north than would be expected given its geographic position). For each species and each data type, we calculated $t_{0}$, the association statistic between the two matrices, and assessed its significance by running 10,000 permutations. For both species, we also measured whether the magnitude of the Procrustes deformations was correlated with certain variables, namely: latitude, longitude, direction of Procrustes errors, whether the population was continental or insular and the size of the land mass containing the population. The size of the land mass was calculated by measuring the perimeter of an island or terrestrial shoreline. All correlations were tested using the R package "VEGAN" in the script Correlations. R.

\subsection{Ocean current analysis}

We tested the relative importance of geographic distance and environmental distance (i.e., geographic distance scaled using the effects of ocean currents) using partial Mantel tests implemented in the R package "VEGAN." For each population pair, we considered the geographic distance to be the Euclidean distance between the sampling locations, and we considered environmental distance to be the Euclidean distance plus the distance added due to ocean currents preventing propagules from moving in a straight-line distance between two populations (Figure 1). We downloaded gridded ocean current data from NOAA (https://ferret.pmel.noaa.gov/); each file contained either the northward or eastward water velocity for each marine pixel (resolution: $1 / 12^{\circ}$ ) in the study area over a 24 -hour period. We downloaded data for 12 time points spaced over two years (February 2014-January 2016), ensuring that each month of the year was represented once to account for seasonal variation in current velocity. We averaged the northward velocities and eastward velocities for all time periods and then created a single grid layer by 

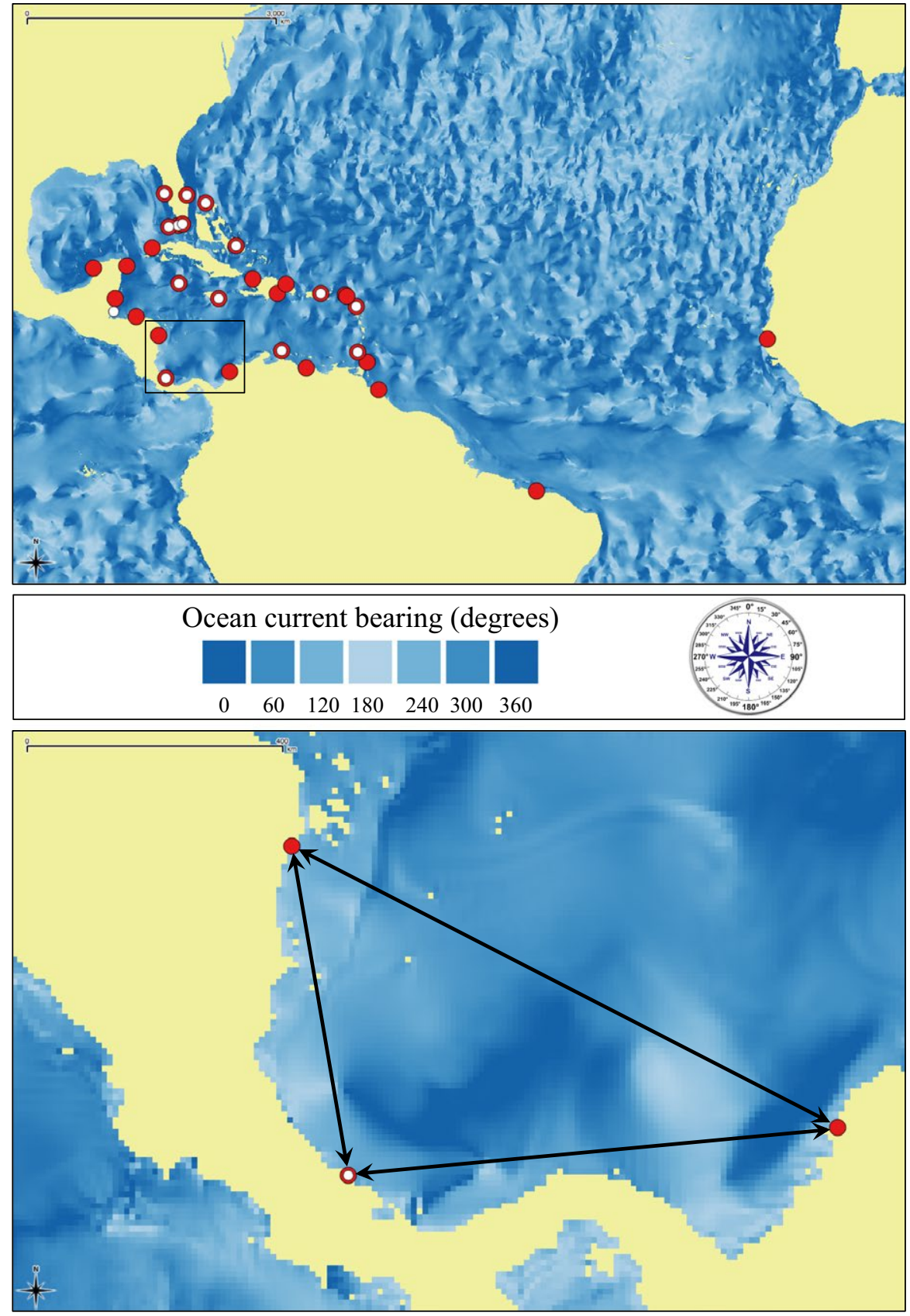

FIGURE 1 In the top panel, sampling locations for white mangroves (Laguncularia racemosa; white dots) and red mangroves (Rhizophora mangle; red dots) are shown, and the black rectangle indicates the geographic extent of the bottom panel. GPS coordinates are listed for each sampling location in Supplemental Table 1. The bottom panel depicts three sampling locations and the arrows show the Euclidean distance between each sampling location. In both panels, the ocean is color coded according to the bearing in degrees of each marine pixel. The bearing values in every pixel that intersects a line segment connecting two sampling locations (i.e., the Euclidean distance) were used to calculate the penalized ocean current distance matrix [Colour figure can be viewed at wileyonlinelibrary.com] determining the ocean current bearing of each cell using the averaged northward and eastward velocities and the "EARTHBEAR" function in the R package "Fossı" (see R script Ocean.R).

The straight-line distance between each pair of populations was measured, and we then identified every grid cell in the averaged layer that intersected the line. If the bearing of a pixel were identical to the bearing of the line, the pixel would be given a score of zero. If the bearing of the pixel were different from the bearing of the line, it would be given a score between zero and 180, where 180 implies that the ocean current bearing of the pixel is perpendicular to the line connecting the populations. We calculated the bearing of the line for both directions, but only retained the direction that minimized the sum of the absolute deviations from the bearings in the pixels. We then averaged the deviations across all pixels intersected by the line to obtain the scaled environmental distance, which would be greater than the Euclidean distance. In this way, we used the averaged ocean current layer as an environmental resistance layer and measured its importance for explaining geographic patterns of genetic variation. Due to the coarse resolution of the gridded layers, some sampling locations appeared to be in marine (as opposed to terrestrial) pixels. Therefore, for this analysis, some GPS coordinates were shifted slightly to ensure that each sampling location was located on a terrestrial pixel. The data acquisition and processing were completed using the script Ocean.R. We followed Massatti, Doherty, and Wood (2017) and used partial Mantel tests to measure the correlation between distances penalized by ocean current and genetic distances (i.e., pairwise $F_{S T}$ ), controlling for Euclidean geographic distance separating populations. 


\section{8 | Pollen vs. seed analysis}

The maternally inherited chloroplast genome and the biparentally inherited nuclear genome have different evolutionary histories and as such will exhibit different amounts of genetic differentiation among sampling locations. In both red and white mangroves, the chloroplast is presumably maternally inherited, given well-documented evidence of maternal transmission in multiple closely related taxa (i.e., several representatives from families in the same order as each mangrove species; Zhang, Liu, \& Sodmergen, 2003). When the rate of seed migration is smaller than that of pollen migration, population genetic theory predicts that greater subpopulation structure will be detected in (maternally inherited) chloroplast markers than in (biparentally inherited) nuclear markers (Petit et al., 2004). The maternal contribution to gene flow can be measured using chloroplast markers, and the paternal contribution to gene flow can be calculated by subtracting the maternal contribution to gene flow from the biparental contribution to gene flow. Thus, the ratio of seed migration to pollen migration $(r)$ can be calculated using the following equation: $r=(A-2 C) / C$, where $A=\left(1 / F_{\text {STnuclear }}\right)-1$, and $C=\left(1 / F_{\text {STchloroplast }}\right)-1$ (Hamilton \& Miller, 2002). We used $F_{\mathrm{ST}}$ to calculate the ratio of seed migration to pollen migration for each species in a pairwise fashion for all pairs of sampling locations.

\section{3 | RESULTS}

\subsection{Geographic structuring of genetic variation}

In both mangrove species, we found greater differentiation among sampling locations in chloroplast DNA vs. nuclear DNA (Supporting Information Tables S2 and S3). Pairwise $F_{S T}$ estimated for red mangroves using RAD loci was usually low, ranging from 0 to 0.679 (average $F_{\mathrm{ST}}=0.209$; Supporting Information Table S2), and pairwise $F_{\mathrm{ST}}$ using chloroplast DNA ranged from 0.138 to 1.0 (average $F_{S T}=0.561$; Supporting Information Table S3). Sampling locations on the margins of the study region (e.g., Anguilla, Senegal, New Port Richey) usually had higher values of pairwise $F_{S T}$ (Supporting Information Table S2). There is a large range in the pairwise genetic differentiation estimated by chloroplast DNA for white mangroves $\left(F_{\mathrm{ST}}\right.$ ranges from 0.075 to 1.0 with average $F_{\mathrm{ST}}=0.506$; Supporting Information Table S3), and the pairwise $F_{S T}$ values for RAD loci vary from low differentiation $\left(F_{\mathrm{ST}}=0.0\right.$ between several Florida and Grand Bahamas populations; Supporting Information Table S2) to high differentiation $\left(F_{\mathrm{ST}}=0.595\right.$ between a Florida population (Melbourne) and Antigua; Supporting Information Table S2). The average pairwise $F_{\mathrm{ST}}$ using RAD loci in white mangroves was 0.285 . The ratio of seed migration to pollen migration $(r)$, calculated using the $F_{\mathrm{ST}}$ values for both species for both genomes, showed greater pollen gene flow than seed gene flow in red mangroves (ratio of pollen:seed $=7.87$ ). In white mangroves, the ratio of pollen:seed gene flow is 0.16 , indicating that the lower genetic differentiation among populations most likely is attributable to propagule, rather than pollen, dispersal.
The SVDQUARTETS trees showed that individuals and sampling locations were often clustered by geography when using nuclear loci (i.e., RAD-Seq data; Figure 2). Notably, several major clades in each species clustered geographically. In red mangroves, the following clades containing more than one sampling location had 100\% bootstrap support: Florida, Florida + Cuba + Grand Bahama, Florida + Cuba + Grand Bahama + Belize + Costa Rica (Caribbean) + Colombia + Nicaragua + Mexico + Honduras, and the previous clade + CostaRica (Pacific) + Panama + Aruba + Venezuela + Cayman Islands + Long Island + Jamaica + Hispaniola (Figure 2). These relationships were also observed with high support when using RAXML (Supporting Information Figure S1). Similarly, in white mangroves, multiple clades with $100 \%$ bootstrap support were congruent with geography: Florida + Grand Bahama, Antigua + Aruba + Grenada + Puerto Rico, and the previous two clades + Costa Rica + Belize + Jamaica + Cayman Islands (Figure 2). As in red mangroves, the svdquarTETs and RAXML trees for white mangroves based on RAD-Seq data were largely congruent. The RAXML trees inferred using chloroplast genomes in both species had fewer highly supported clades than trees generated from RAD-Seq data, although there were fewer tips in the chloroplast trees (Supporting Information Figure S2). Additionally, the phylogenetic relationships were less congruent with the geographic relationships of sampling locations than in the nuclear trees. In red mangroves, all Florida samples formed a highly supported clade, as did some individuals from Aruba, Antigua, Grenada and Jamaica-although not all Jamaica or Grenada individuals were represented in the clade. In white mangroves, one notable highly supported clade included samples from Belize, Colombia, Honduras, Hispaniola, Mexico and Puerto Rico-although not all samples from Colombia and Puerto Rico were in the clade. In general, the phylogenetic relationships in the chloroplast trees of white mangroves are less congruent with geography than those of red mangroves.

\section{2 | Dispersal limitations as a function of geographic distance}

Mantel tests were significant for both species when comparing geographic distance matrices with genetic matrices (Table 1); IBD explained at least a portion of genetic variance. Mantel tests are discussed in more detail in the subsequent section, where the results of the partial Mantel tests are summarized. For red mangroves, the Procrustes analysis based on RAD loci indicated that nuclear genetic data were significantly correlated with the geography of the sampling locations $\left(t_{o}=0.561 ; p<0.01\right.$; with Pacific samples included, $t_{0}=0.602$; Figure 3; Supporting Information Figure S3). Similarly, in white mangroves, the Procrustes analysis based on RAD loci revealed that nuclear genetic data were significantly correlated with geography $\left(t_{o}=0.684 ; p<0.01\right.$; Table 2; Figure 4). For red mangroves, the Procrustes analysis also showed that there was not a significant relationship between geographic and genetic distance when using chloroplast data, although the relationship was barely nonsignificant $\left(t_{o}=0.284 ; p=0.0575\right)$. For white mangroves, the Procrustes analysis using chloroplast DNA also found that genes were not significantly 


\section{Region}

- Central America

— Florida/Bahamas

- Greater Antilles

— Lesser Antilles

South America

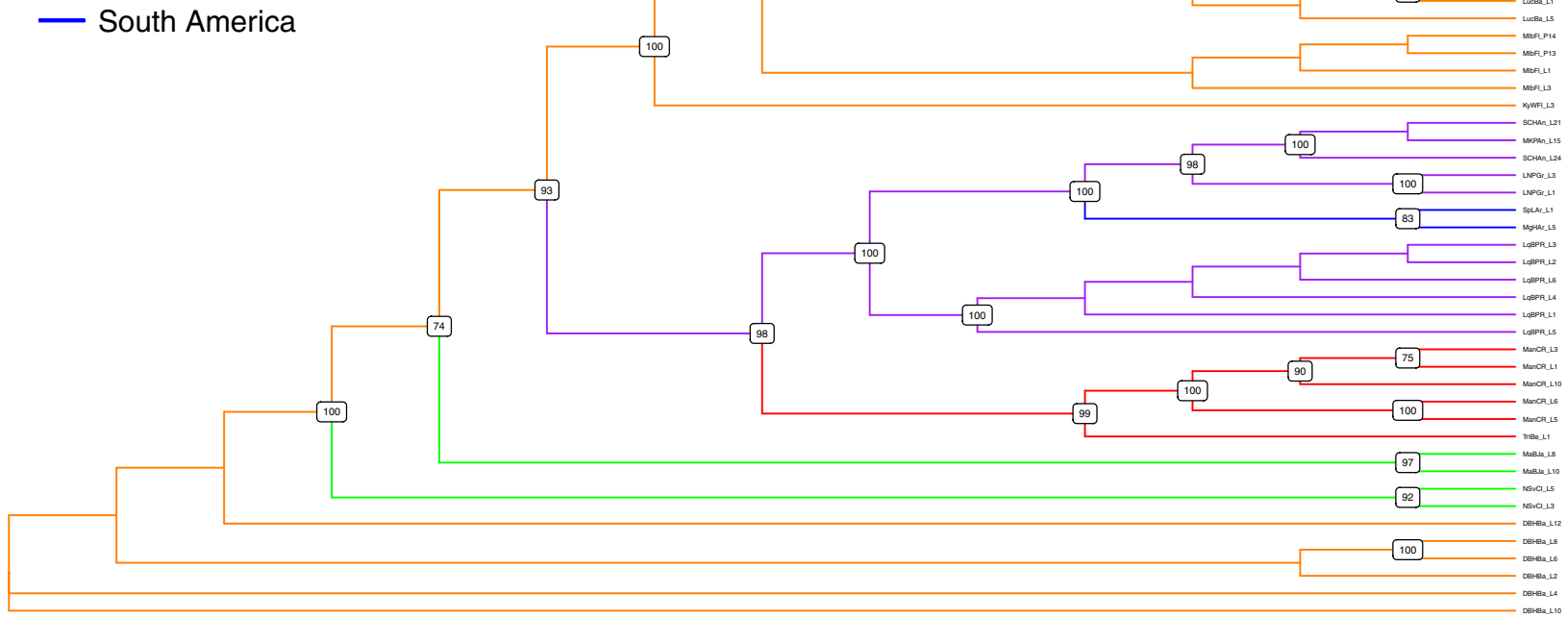

Region

- Africa/Brazil

- Central America

- Florida/Bahamas

- Greater Antilles

— Lesser Antilles

- South America

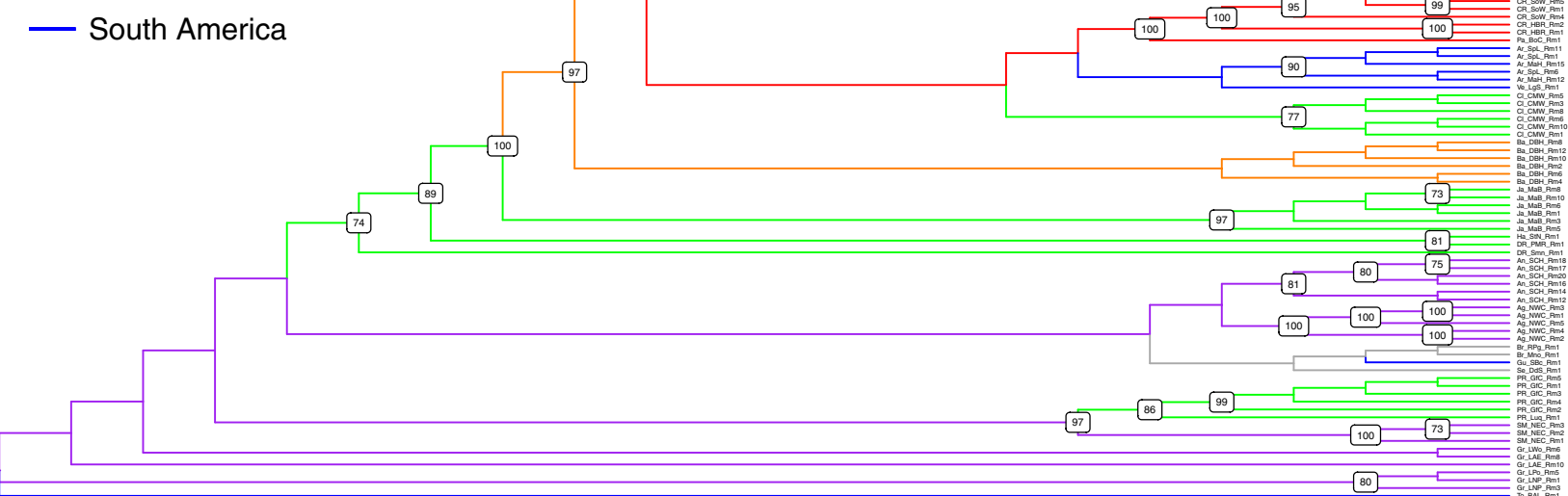

FIGURE 2 The SVDQuartets trees for white mangroves (Laguncularia racemosa; top panel) and red mangroves (Rhizophora mangle; bottom panel) inferred using RAD-Seq loci are shown. The color of each branch indicates the geographic region where the individual was sampled. Bootstrap values $>70 \%$ are indicated on the nodes [Colour figure can be viewed at wileyonlinelibrary.com]

correlated with geography $\left(t_{0}=0.0808 ; p=0.845\right)$. In white mangroves, the magnitude of deformations from the Procrustes analysis was significantly correlated with both latitude and longitude, but not with three other factors associated with sampling locations (island vs. continental location, island size, direction of Procrustes deformations; Table 3). In contrast, all five factors associated with sampling locations 
TAB LE 1 Mantel tests assess the significance between genetic and geographic distance, genetic and ocean current penalized distance, and partial Mantel tests assess the impact of ocean current penalized distance while controlling for covariance from geographic distance

\begin{tabular}{llllll} 
& \multicolumn{2}{l}{$\begin{array}{l}\text { Laguncularia } \\
\text { racemosa }\end{array}$} & & \multicolumn{2}{l}{ Rhizophora mangle } \\
\cline { 2 - 3 } & $r$ & $p$ & & $r$ & $p$ \\
Mantel (Geography) & 0.694 & $0.001^{* *}$ & & 0.426 & $0.01^{*}$ \\
Mantel (Ocean) & 0.275 & $0.011^{*}$ & & 0.126 & $0.046^{*}$ \\
Partial Mantel & 0.249 & $0.021^{*}$ & & 0.242 & $0.001^{* *}$ \\
\hline
\end{tabular}

Note. ${ }^{*}$ Significant when $\alpha=0.05,{ }^{* *}$ significant when $\alpha=0.01,{ }^{* * *}$ significant when $\alpha=0.001$ ).

were significantly correlated with the magnitude of Procrustes errors in red mangroves (Table 3).

\section{3 | Dispersal mediated by ocean current}

In both red and white mangroves, Mantel tests were significant when comparing geographic distance and genetic distance $\left(F_{\mathrm{ST}}\right)$, and when comparing ocean current penalized distance and genetic distance (Table 1). In white mangroves, the $r$-value was higher in the Mantel test for geography $(r=0.694)$ than in ocean current penalized distance $(r=0.275$; Table 1$)$. There was a similar trend in red mangroves $(r=0.426$ for geographic distance; $r=0.126$ for ocean current penalized distance), and both $r$-values in red mangroves were lower than the corresponding value in white mangroves. Additionally, partial Mantel tests were significant ( $r=0.249$ for white mangroves and $r=0.242$ for red mangroves; Table 1) and revealed that the ocean current penalty matrices explained some of the variation in spatial genetic patterns when controlling for covariance associated with geographic distance.

\section{4 | DISCUSSION}

This study highlights how we can quantify key biotic traits of species to evaluate their interaction with abiotic factors, and how this interaction shapes the spatial distribution of genetic variation within species. Specifically, we investigated how differences in dispersal ability are affected by ocean currents, and how this interaction affects phylogeographic patterns. We predicted that red mangroves would exhibit greater connectivity between

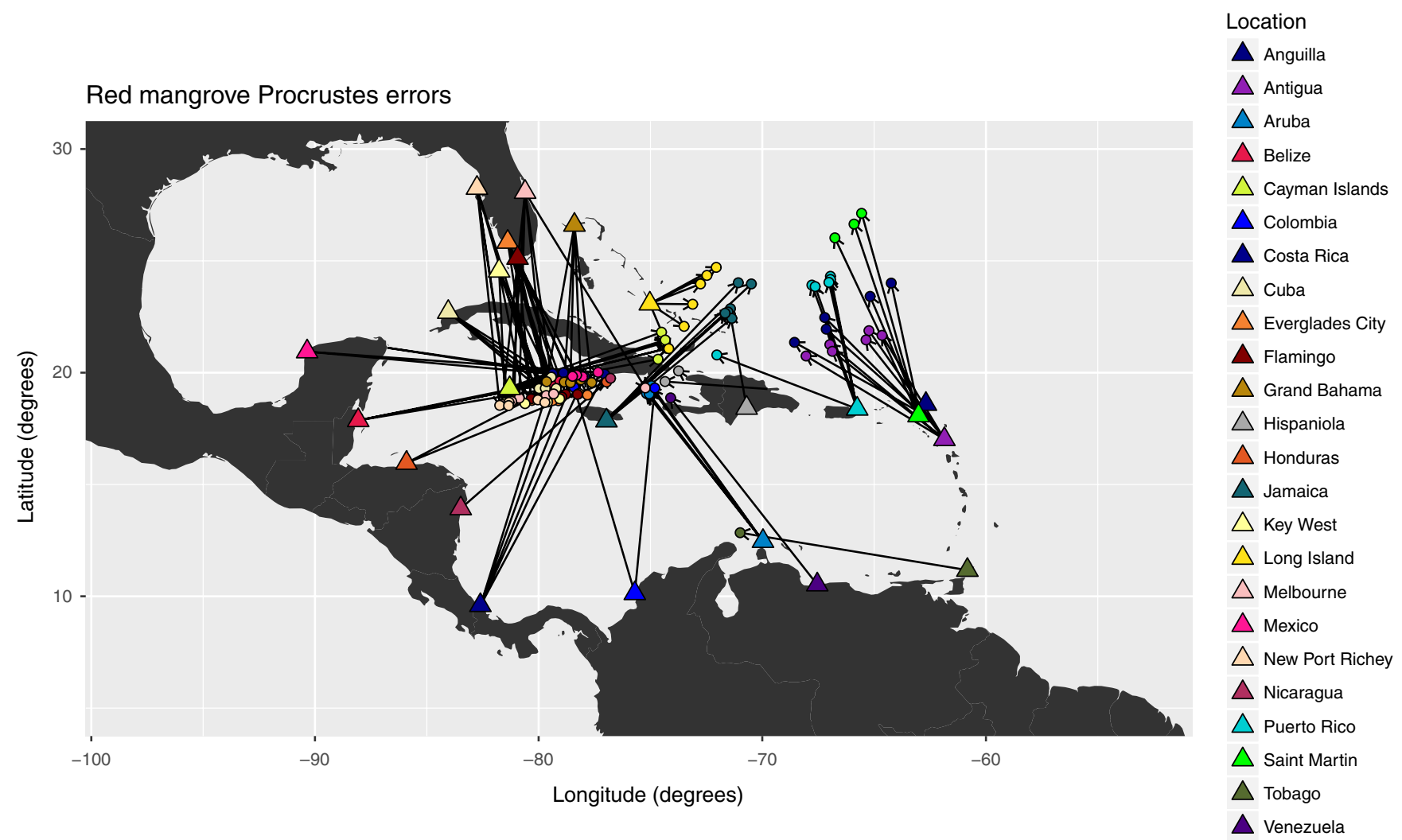

FIGURE 3 The sampling locations for red mangroves, represented by triangles, and the deformations identified by the Procrustes analysis for red mangrove RAD-Seq data are depicted by circles. Arrows show the Procrustes deformation distance and connect the deformation points to the corresponding sampling location. Samples from Brazil, Grenada, Guyana, and Senegal were removed because some individuals in these sampling locations had very large deformations relative to the majority of populations, and made it difficult to visualize the results. Supplemental Figure 2 shows all red mangrove Procrustes results [Colour figure can be viewed at wileyonlinelibrary. com] 
TAB LE 2 The results of the Procrustes analyses in each species for nuclear and chloroplast data

\begin{tabular}{ccccccc}
\cline { 5 - 6 } & \multicolumn{2}{c}{ Laguncularia racemosa } & & \multicolumn{2}{l}{ Rhizophora mangle } \\
\cline { 5 - 6 } & Nuclear & Chloroplast & & Nuclear & Chloroplast \\
$t_{0}$ & 0.684 & 0.808 & & 0.561 & 0.284 \\
$p$ & $<0.001^{* * *}$ & 0.845 & & $<0.001^{* * *}$ & 0.058 \\
\hline
\end{tabular}

Notes. For each species and each marker type, the $t_{0}$ value and $P$ value are shown.

***significant when $\alpha=0.001$

populations through seeds than white mangroves and that the patterns of genetic differentiation would reflect differences in the degree of isolation among populations as a function of the geographic distance separating populations, augmented by oceanic currents. Here, we showed that comparative phylogeographic patterns observed in the two mangrove species, combined with spatially explicit analyses to assess abiotic drivers of phylogeographic patterns (i.e., ocean currents), revealed that species-specific dispersal traits such as propagule movement were important for patterning spatial genetic diversity-sometimes in unexpected ways-and that they were not the only important factor. Severa key results supported the importance of ocean currents transporting propagules, but there was also evidence that other means of moving genetic material were important. Phylogenetic, population genetic differentiation, and IBD analyses indicated both concordant and discordant phylogeographic patterns when we compared these two mangrove species adapted for ocean dispersal. Here, we showed that ocean currents act as a mechanism for facilitating dispersal using spatially explicit tests of the role of ocean currents on patterning genetic diversity. Additionally, we measured relative amounts of pollen vs. propagule gene flow, which indicated critical differences between the two species regarding the importance of propagule movement. Contrary to expectations, white mangroves exhibited greater connectivity between populations through seeds than red mangroves. Importantly, methods in this study can be applied to many other species with spatial patterns of genetic variation impacted by both biotic and abiotic factors; below, we discuss the implications of our results, focusing on how our findings impact understanding of how species-specific biotic traits and abiotic factors interact to shape phylogeographic patterns.

\section{1 | Concordance and discord between species adapted for ocean dispersal}

Several types of evidence supported similar phylogeographic patterns in the two mangrove species investigated. Measures of population differentiation revealed a wide range of interpopulation genetic differentiation in both species; typically, more proximate populations had lower differentiation (Supporting Information Tables S2 and S3). Additionally, Mantel tests for IBD showed that Euclidean distance between populations was a significant predictor of genetic distance $\left(F_{\mathrm{ST}}\right)$ between populations in the nuclear genome for each species (Table 1). Phylogenetic analyses of each species corroborated this interpretation, as individuals from the same population or region often grouped together (Figure 2, Supporting Information

White mangrove Procrustes errors

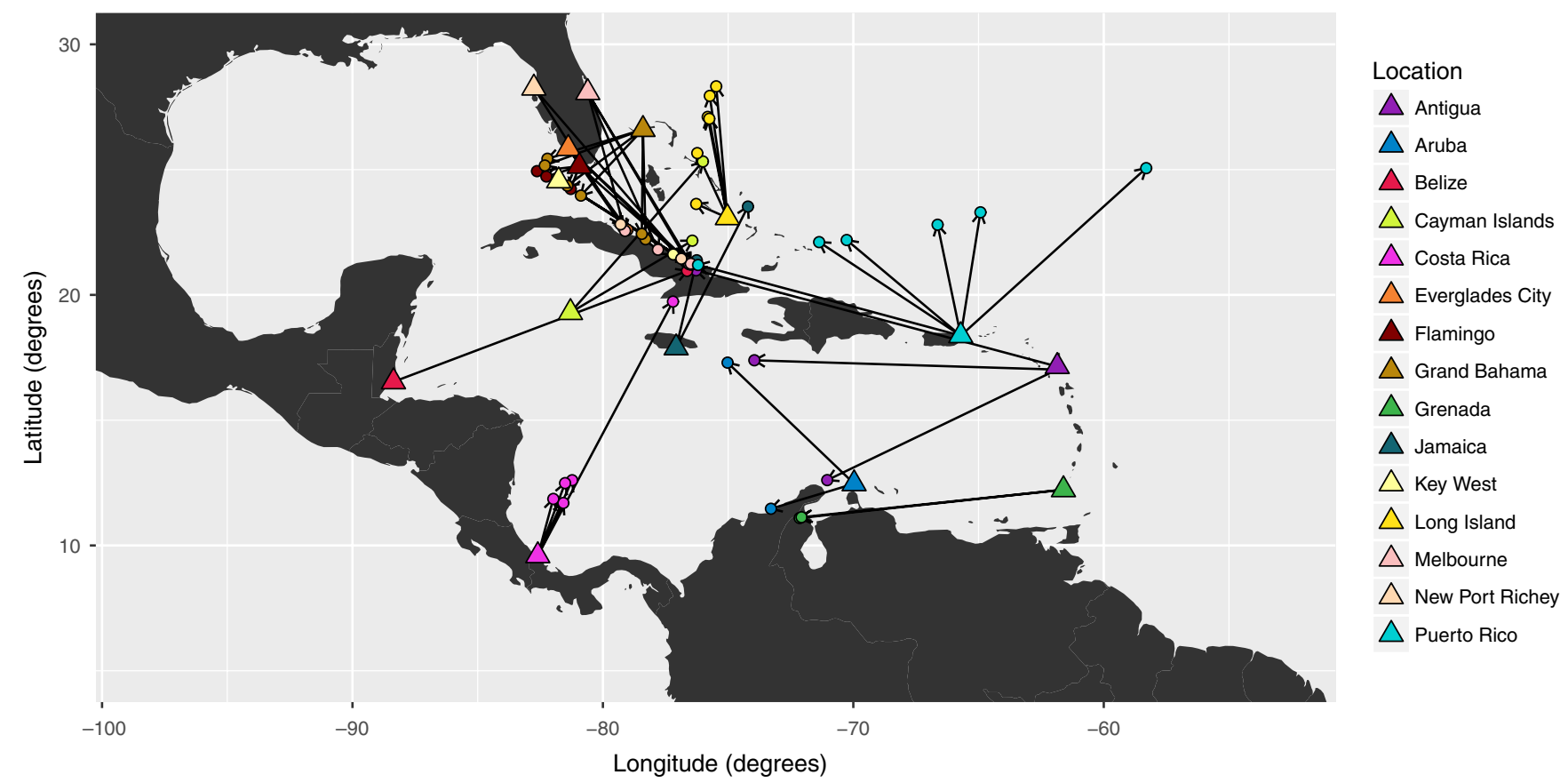

FIG URE 4 The sampling locations for white mangroves are represented by triangles, and the deformations identified by the Procrustes analysis for white mangrove RAD-Seq data are depicted by circles. Arrows show the Procrustes deformation distance and connect the deformation points to the corresponding sampling location [Colour figure can be viewed at wileyonlinelibrary.com] 
TAB LE 3 The results of correlation tests between the magnitude of Procrustes deformations and factors associated with sampling locations. For each species, five factors were tested for correlation against the Procrustes deformations from the RAD-Seq data

\begin{tabular}{|c|c|c|c|c|}
\hline & \multicolumn{2}{|c|}{ Laguncularia racemosa } & \multicolumn{2}{|c|}{ Rhizophora mangle } \\
\hline & F-value & $p$ & $F$-value & $p$ \\
\hline $\begin{array}{l}\text { Island vs. } \\
\text { continental }\end{array}$ & 0.18 & 0.68 & 4.23 & $0.042^{*}$ \\
\hline Island size & 0.23 & 0.8 & 3.75 & $0.026^{*}$ \\
\hline Direction & 0.44 & 0.51 & 18.68 & $<0.0001^{* * *}$ \\
\hline Latitude & 10.92 & $0.001^{* *}$ & 6.77 & $0.010^{*}$ \\
\hline Longitude & 14.94 & $<0.0001^{* * *}$ & 73.2 & $<0.0001^{* * *}$ \\
\hline
\end{tabular}

Note. ${ }^{*}$ significant when $\alpha=0.05,{ }^{* *}$ significant when $\alpha=0.01,{ }^{* * *}$ significant when $\alpha=0.001$.

Figures S1 and S2). However, there were key differences between the species: we detected greater differentiation between sampling locations in both nuclear and chloroplast data in white mangroves than in red mangroves (Supporting Information Tables S2 and S3), suggesting that some mechanism makes genetic exchange easier between populations of red mangroves than white mangroves. Several results indicated that LDD via water might not be as important as has been assumed. Specifically, IBD and Procrustes analyses revealed important insights about the patterns of genetic diversity in each of the species (Figures 3 and 4, Tables 1 and 2). Genetic differentiation in the nuclear genome of both species was partially determined by geography-indicating that successful LDD events in these species were not the only process shaping spatial patterns of genetic diversity for the species.

\subsection{Ocean currents as a mechanism for dispersal}

LDD via ocean currents is often considered the only important mechanism that moves genetic material between distant populations of mangroves (Tomlinson, 2016). Our results show that ocean currents may not be as important as assumed, but they do have a role in transporting propagules frequently enough to impact genetic diversity between populations (Table 3 ). Ocean currents had an effect on spatial genetic patterns in both species, as shown in the ocean current analysis (Figure 1, Table 1). However, ocean currents were not the only significant predictor of genetic patterns: Mantel and partial Mantel tests revealed that geographic distance was also important (Table 1). This implies that LDD via ocean currents is an important driver of genetic patterns in red and white mangroves, but that other processes, such as genetic drift, which led to IBD patterns, need to be considered. Historical factors, such as past environmental or physical barriers between populations, or changes in ocean currents and/or wind patterns, could have also affected estimates of pairwise $F_{\mathrm{ST}}$, and accordingly could impact IBD and other downstream analyses.
Key distinctions between island and continental populations exist in these two species that can disperse between the two land types. The magnitude of Procrustes deformations in each species was correlated with environmental factors, such as island size, longitude, latitude and direction of deformation (Table 3). Many mangrove populations, especially small populations, could have been recently founded, or could be readily extirpated in a major storm event-making it important to consider a variety of historical processes that could have led to the current patterns of genetic variation among populations. In the Procrustes analysis of red mangroves, the deviations from expected patterns of variation under IBD are in the direction of the Cayman Islands, indicating that individuals from geographically distant populations are nonetheless very similar genetically to individuals sampled in the Cayman Islands; one potential hypothesis explaining this pattern is recent migration (Figure 3). In addition to ocean currents, other abiotic factors influenced observed genetic patterns-in red mangroves, island size was correlated with the Procrustes deformations that assessed discordance between genes and geography; islands with less coastline are less likely to be a landing spot for drifting propagules (Table 3). This pattern was not detected in white mangroves, meaning that propagule movement in white mangroves may be sufficient to counteract the effect of island size (Table 3). In general, smaller islands had larger deformations, meaning that in small islands, genetic differentiation was more different than expected based on geography, as compared to large islands. Propagule dispersal was less important than expected in red mangroves, so successful colonization or immigration via propagules may be very rare and subject to stochastic effects regarding propagule origin. As island size alone was not able to explain the Procrustes deformations in both species, this result highlights the importance of considering both species-specific biotic traits and abiotic factors in comparative phylogeography studies.

\subsection{The importance of propagule dispersal relative to pollen}

Biotic factors other than propagule dispersal are important for determining genetic patterns. We collected genetic data from both the nuclear and chloroplast genomes so we could assess the relative importance of gene flow via propagules and gene flow via other processes (i.e., pollen movement). In white mangroves, propagule movement is important-seeds are approximately six times as important for moving genes as is pollen. However, in red mangroves, propagule movement is not nearly as important; the contribution of pollen to the movement of genes is almost eight times greater than that of propagules. Contrary to our predictions, propagule movement in red mangroves was less than in white mangroves. The result for red mangroves strongly contradicts our expectation-the large, long-lived red mangrove propagules were predicted to contribute heavily to spatial patterns of genetic diversity. In white mangroves, we expected that propagules would contribute more to the genetics of the species than pollen, although the relative importance of 
propagules to pollen in white mangroves as compared to red mangroves is surprising.

Our results indicate that ocean currents may not be the major driving force of dispersal in red mangroves, as currently assumed (Nettel \& Dodd, 2007; Takayama, Tamura, Tateishi, Webb, \& Kajita, 2013; Wee et al., 2015; Hodel, Cortez, Soltis, \& Soltis, 2016; reviewed in Tomlinson, 2016). For a typical wind-pollinated plant species, red mangrove pollen movement was perhaps not unexpected. In empirical studies, the rate of pollen movement is often at least one order of magnitude larger than the rate of seed movement (Petit et al., 2004). However, one would expect viviparous mangrove species, that purportedly have the ability to disperse long distances using ocean currents, to have a lower pollen:seed ratio. Our findings for white mangroves seem more in line with expectations for a mangrove species: a low pollen:seed ratio for a "typical" plant, but expected because of its dispersal mechanism. As noted previously, pairwise $F_{S T}$ can account for both historical factors and ongoing gene flow, so the inferred amounts of pollen- and seed-mediated gene flow may not be solely due to contemporary gene flow.

In summary, the pollen:seed ratio in red mangroves is surprisingly high for a mangrove species, whereas that of white mangroves more closely matches expectations. A previous study of black mangroves (Avicennia germinans; Acanthaceae), another mangrove species distributed throughout the Caribbean, found a pollen:seed ratio of 5.1 (Nettel \& Dodd, 2007). Black mangrove propagules are intermediate in size and longevity between those of white and red mangroves, and black mangrove parent plants occur at an intermediate distance from the water compared to the two focal species of this study. The results for black mangroves imply that smaller propagules may be more valuable for LDD in mangrove systems, as the pollen:seed ratio for black mangroves is smaller than that of red mangroves. The Nettel and Dodd (2007) study used few markersonly two polymorphic chloroplast SSRs-so their chloroplast $F_{\mathrm{ST}}$ estimates would be expected to have large variance.

Many studies of mangrove genetic diversity (e.g., studies that used microsatellites) use ocean currents to explain the geographic distribution of genetic variation (Hodel et al., 2016; Nettel \& Dodd, 2007; Takayama et al., 2013; Wee et al., 2015). This approach is logical, as mangrove species have various types of vivipary, and propagules can float in salt water for months, often establishing in suitable substrate many kilometres away (Rabinowitz, 1978). However, propagules are not the only means of transmitting genetic material-pollen can be critically important in patterning genetic diversity as well. Wind pollination, which typically moves pollen greater distances than transport via insects, characterizes red mangroves, in contrast to white mangroves, which are insectpollinated (Tomlinson, 2016). Both species are self-compatible, and red mangroves have been documented to produce fruit from selfpollination at approximately one tenth of the frequency of wind pollination (Nadia \& Machado, 2014). White mangrove flowers have been observed to self-pollinate when not visited by insects (Landry, 2013). Although both of these pollination syndromes can move genetic material via pollen, the majority of gene flow in mangrove species is assumed to occur via propagules, but until now, this had not been tested with genetic data in a spatially explicit context. Although differences in pollination syndrome could have impacted the results, our analyses demonstrated that propagule movement is more important than pollen in determining spatial patterns of genetic variation in white mangroves, but that the opposite was true in red mangroves.

\subsection{Applications to other species}

Differences in dispersal ability between taxa can leave subtly different genetic signatures that require high-resolution data to tease apart. Historically, comparative phylogeography studies typically used single-locus DNA sequences (i.e., mitochondrial or chloroplast DNA) or nuclear microsatellite loci (Avise, 2000; Soltis, Morris, McLachlan, Manos, \& Soltis, 2006). The number of markers used frequently numbered fewer than $\mathbf{2 0}$ microsatellites or fewer than 10 linked regions on the chloroplast or mitochondrial genomes. Adequately testing dispersal requires sufficient resolution in different genomes (i.e., both nuclear and organellar). Recent studies have embraced using many more (i.e., thousands) loci, such as phylogeographic studies using RAD-Seq data (reviewed in Andrews, Good, Miller, Luikart, \& Hohenlohe, 2016). However, many comparative phylogeographic studies do not sample loci from both the nuclear and organellar genomes (Riddle, 2016). Even though organellar genomes are effectively single loci, the differences in their inheritance compared to the nuclear genome make including organellar data valuable for phylogeographic inference (Petit et al., 2004). For instance, in an animal species with biased sex ratios and/or differences in mobility between the sexes, mitochondrial and nuclear data would provide different inferences of dispersal. Similarly, in a plant species with vast differences in the amount of dispersal possible via seeds and pollen, the chloroplast and nuclear genomes would show different genomic signatures regarding dispersal.

This study highlighted the importance of ocean currents and species-specific dispersal traits and should inform how future studies consider the interplay of biotic and abiotic traits. Specifically, our study has implications beyond these two mangroves-the results directly apply to species that disperse over oceans and indirectly apply to other species that disperse across some type of barrier. Our results show that for coastal species that use water to facilitate dispersal, it is important to consider all of the mechanisms that spatially pattern genetic diversity. Studies of other water-dispersed plants, such as Hibiscus tiliaceus (Takayama, Kajita, Murata, \& Tateishi, 2006), used chloroplast DNA and detected moderate genetic structure $\left(F_{\mathrm{ST}} \sim\right.$ 0.25 ) between populations not immediately connected by water. However, the choice of markers (i.e., maternally inherited chloroplast DNA) made it impossible to tease apart the effect of pollen on the patterning of genetic diversity across geographic space. As in red mangroves, just because a species expends a lot of energy producing propagules that can disperse long distances, there is no guarantee that the propagules will successfully travel via 
ocean currents to establish new populations or migrate to other distant existing populations. Future studies of water-dispersed plants should use both nuclear and uniparentally inherited organellar markers to assess the relative impacts of seeds and pollen on genetic patterns in the species of interest. Collecting both adequate nuclear and organellar genetic data is a prudent strategy in almost all systems.

\section{5 | CONCLUSIONS}

We investigated how differences in a biotic factor between two species, dispersal-which differed between the species due to propagule size, longevity and the proximity of the parent plant to water-affected geographic patterns of genetic variation. Additionally, this study used explicit modelling of ocean currents, which assessed how much an abiotic factor impacted genetic differentiation between populations by moving propagules. We found that, propagule movement in the ocean is important in both species, and it is actually more important for moving genetic material in white mangroves. Pollen movement, facilitated by wind, may be the driving force behind transporting genetic material between populations of red mangroves. The results of this study will impact how shared phylogeographic patterns are investigated in taxa other than mangroves and coastal species. This study illustrates how it is important to fully investigate subtle differences between species using multiple types of data in a spatially explicit context. Without either the chloroplast or nuclear data, we still could have detected differences in genetic differentiation between species, but we would have been unable to determine the relative importance of propagule vs. pollen gene flow, which was critical to interpreting the results of this study. Furthermore, without explicitly investigating how ocean currents related to genetic differentiation, we would have been unable to explain the geographic patterns of genetic variation beyond an IBD scenario and perhaps may have discounted the importance of LDD in these species. Identifying subtle genetic differences between species requires a carefully designed study and understanding the species-specific biotic factors and abiotic environmental factors that are important for the study system and that led to observed patterns. Future studies comparing species with similar phylogeographic patterns should use data from both nuclear and organellar genomes and incorporate relevant biotic and abiotic drivers of intraspecific genetic variation, such as life history traits (e.g., dispersal, as in this study) or environmental data (e.g., spatially explicit ocean current data). Increasingly, it will be possible to investigate thoroughly the biotic and abiotic influences on genetic diversity, as more resources such as genomic data, digitized specimen records and environmental data layers become available and can be integrated (Soltis \& Soltis, 2017).

Finally, investigating the phylogeography of these two mangrove species also has practical applications. Coastal species are often more vulnerable to the effects of climate change than plants occupying inland habitats (Barbier et al., 2011; Christensen, 2000; Tomlinson, 2016). Mangroves provide crucial ecosystem services: mitigating damage due to storm surges, providing habitat for animal species and filtering water (Barbier et al., 2011; Ewel, Twilley, \& Ong, 1998; Rönnbäck, 1999; Walters et al., 2008). Anthropogenic climate change, overdevelopment of coastal areas, and increased shipping are negatively impacting mangroves (Kristensen, Bouillion, Dittmar, \& Marchand, 2008). Conservation genetics theory has shown the importance of characterizing genotypes present in natural populations to combat deleterious forces such as inbreeding depression, outbreeding depression, decline in genetic diversity, and loss of genetic adaptive potential (Crandall, Bininda-Emonds, Mace, \& Wayne, 2000; Frankham, 2005; Moritz, 1994). Our improved understanding of the phylogeographic structure of mangroves will enable the efficient protection of these crucial coastal tree species throughout the Caribbean. Based on the results of this study, if it is not possible to use local propagules in restoration/re-introduction, locations that were identified as source populations should be used as propagule sources because there is a history of successful migration and colonization from those locations.

\section{ACKNOWLEDGEMENTS}

We thank the following people for help collecting leaf tissue: Dr. Andrew Crowl, Dr. Pablo Allen, Kelly Speer, Dr. Riccardo Baldini, D'Shan Maycock and Lori-Ann Harris. We thank the following for help with laboratory work: Veronica Moiño and Wade Chen. We thank the following agencies for allowing us to collect leaf tissue and for facilitating field collections: Bahamas Department of Agriculture, Jamaica National Environment and Planning Agency, Jamaica Urban Development Corporation, Cayman Islands Department of Environment, Aruba Department of Agriculture, Husbandry and Fisheries. We thank the NYBG for allowing us to sample from herbarium specimens.

\section{AUTHOR CONTRIBUTIONS}

The research was designed by R.G.J.H., P.S.S. and D.E.S. The research was performed by R.G.J.H., A.C.P. and J.F.D. The reagents and analytical tools were contributed by R.G.J.H., L.K.K., S.F.M., P.S.S. and D.E.S. The data were analysed by R.G.J.H., A.C.P. and J.F.D. The paper was written by R.G.J.H., L.K.K., S.F.M., P.S.S. and D.E.S.

\section{DATA ACCESSIBILITY}

DNA Sequences: Raw reads from the RAD-Seq libraries (accession numbers SRR7501584-SRR7501638; SRR7504176-SRR7504186) and chloroplast genomes (accession numbers SRR7779779-SRR 7779767; SRR7781534-SRR7781581) are deposited in the NCBI SRA. Supplemental files, including DNA matrices, sampling locations and ocean current files, are deposited in the Dryad Digital Repository: https://doi.org/10.5061/dryad.53mp5ng. Scripts are publicly available on Github; repository location: https://github. com/richiehodel/Caribbean_mangroves. 


\section{ORCID}

Richard G. J. Hodel (ID http://orcid.org/0000-0002-2896-4907

\section{REFERENCES}

Allen, J. A., \& Krauss, K. W. (2006). Influence of propagule flotation longevity and light availability on establishment of introduced mangrove species in Hawai'i. Pacific Science, 60, 367-376. https://doi. org/10.1353/psc.2006.0015

Andrews, K. R., Good, J. M., Miller, M. R., Luikart, G., \& Hohenlohe, P. A. (2016). Harnessing the power of RADseq for ecological and evolutionary genomics. Nature Reviews Genetics, 17, 81-92. https://doi. org/10.1038/nrg.2015.28

Avise, J. C. (2000). Phylogeography: The history and formation of species. Cambridge, MA: Harvard University Press.

Avise, J. C., Alisauskas, R. T., Nelson, W. S., \& Ankney, C. D. (1992). Matriarchal population genetic structure in an avian species with female natal philopatry. Evolution, 46, 1084-1096. https://doi. org/10.1111/j.1558-5646.1992.tb00621.x

Barbier, E. B., Hacker, S. D., Kennedy, C., Koch, E. W., Stier, A. C., \& Silliman, B. R. (2011). The value of estuarine and coastal ecosystem services. Ecological Monographs, 81, 169-193. https://doi. org/10.1890/10-1510.1

Burban, C., \& Petit, R. J. (2003). Phylogeography of maritime pine inferred withorganellemarkershaving contrastedinheritance.MolecularEcology, 12, 1487-1495. https://doi.org/10.1046/j.1365-294X.2003.01817.x

Carnaval, A. C., Hickerson, M. J., Haddad, C. F. B., Rodrigues, M. T., \& Moritz, C. (2009). Stability predicts genetic diversity in the Brazilian Atlantic forest hotspot. Science, 323, 785-789. https://doi. org/10.1126/science.1166955

Chifman, J., \& Kubatko, L. (2014). Quartet inference from SNP data under the coalescent model. Bioinformatics, 30, 3317-3324. https://doi. org/10.1093/bioinformatics/btu530

Christensen, N. L. (2000). North American terrestrial vegetation. Cambridge, UK: Cambridge University Press.

Crandall, K. A., Bininda-Emonds, O. R. P. O., Mace, G. M., \& Wayne, R. K. (2000). Considering evolution processes in conservation biology. Trends in Ecology \& Evolution, 15, 290-295. https://doi.org/10.1016/ S0169-5347(00)01876-0

de Queiroz, A. (2005). The resurrection of oceanic dispersal in historical biogeography. Trends in Ecology \& Evolution, 20, 68-73. https://doi. org/10.1016/j.tree.2004.11.006

Doyle, J. J., \& Doyle, J. L. (1987). A rapid DNA isolation procedure for small quantities of fresh leaf tissue. Phytochemical Bulletin, 19, 11-15.

Eaton, D. A. R. (2014). PyRAD: Assembly of de novo RADseq loci for phylogenetic analyses. Bioinformatics, 30, 1844-1849. https://doi. org/10.1093/bioinformatics/btu121

Ewel, K. C., Twilley, R. R., \& Ong, J. E. (1998). Different kinds of mangrove forests provide different goods and services. Global Ecology \& Biogeography Letters, 7, 83-94. https://doi.org/10.2307/2997700

Frankham, R. (2005). Stress and adaptation in conservation genetics. Journal of Evolutionary Biology, 18, 750-755. https://doi. org/10.1111/j.1420-9101.2005.00885.x

Galindo, H. M., Olson, D. B., \& Palumbi, S. R. (2006). Seascape genetics: A coupled oceanographic-genetic model predicts population structure of Caribbean corals. Current Biology, 16, 1622-1626. https://doi. org/10.1016/j.cub.2006.06.052

Gillespie, R. G., Baldwin, B. G., Waters, J. M., Fraser, C. I., Nikula, R., \& Roderick, G. K. (2011). Long-distance dispersal: A framework for hypothesis testing. Trends in Ecology \& Evolution, 27, 47-56.

Goudet, J. (2005). hierfstat, a package for R to compute and test hierarchical F-statistics. Molecular Ecology Notes, 5, 184-186. https://doi. org/10.1111/j.1471-8286.2004.00828.x
Hamilton, M. B., \& Miller, J. R. (2002). Comparing relative rates of pollen and seed gene flow in the island model using nuclear and organelle measures of population structure. Genetics, 162, 1897-1909.

Heaney, L. R., Walsh, J. S., \& Townsend Peterson, A. (2005). The roles of geological history and colonization abilities in genetic differentiation between mammalian populations in the Philippine archipelago. Journal of Biogeography, 32, 229-247. https://doi. org/10.1111/j.1365-2699.2004.01120.x

Hodel, R. G., Chen, S., Payton, A. C., McDaniel, S. F., Soltis, P., \& Soltis, D. E. (2017). Adding loci improves phylogeographic resolution in red mangroves despite increased missing data: Comparing microsatellites and RAD-Seq and investigating loci filtering. Scientific Reports, 7, 17598. https://doi.org/10.1038/s41598-017-16810-7

Hodel, R. G. J., Cortez, M. B., Soltis, P. S., \& Soltis, D. E. (2016). Comparative phylogeography of black mangroves (Avicennia germinans) and red mangroves (Rhizophora mangle) in Florida: Testing the maritime discontinuity in coastal plants. American Journal of Botany, 103, 730-739. https://doi.org/10.3732/ajb.1500260

Huang, H., \& Knowles, L. L. (2016). Unforeseen consequences of excluding missing data from next-generation sequences: Simulation study of RAD sequences. Systematic Biology, 65, 357-365. https://doi. org/10.1093/sysbio/syu046

Humphries, C. J., \& Parenti, L. R. (1999). Cladistic biogeography: Interpreting patterns of plant and animal distributions. Oxford, UK: Oxford University Press.

Juan, C., Emerson, B. C., Oromí, P., \& Hewitt, G. M. (2000). Colonization and diversification: Towards a phylogeographic synthesis for the Canary Islands. Trends in Ecology \& Evolution, 15, 104-109. https:// doi.org/10.1016/S0169-5347(99)01776-0

Kearse, M., Moir, R., Wilson, A., Stones-Havas, S., Cheung, M., Sturrock, S., ... Thierer, T. (2012). Geneious Basic: An integrated and extendable desktop software platform for the organization and analysis of sequence data. Bioinformatics, 28, 1647-1649. https://doi. org/10.1093/bioinformatics/bts199

Kinlan, B. P., \& Gaines, S. D. (2003). Propagule dispersal in marine and terrestrial environments: A community perspective. Ecology, 84, 2007-2020. https://doi.org/10.1890/01-0622

Kristensen, E., Bouillion, S., Dittmar, T., \& Marchand, C. (2008). Organic carbon dynamics in mangrove ecosystems: A review. Aquatic Botany, 89, 201-219. https://doi.org/10.1016/j.aquabot.2007.12.005

Landry, C. L. (2013). Pollinator-mediated competition between two co-flowering Neotropical mangrove species, Avicennia germinans (Avicenniaceae) and Laguncularia racemosa (Combretaceae). Annals of Botany, 111, 207-214. https://doi.org/10.1093/aob/mcs265

Langmead, B., \& Salzberg, S. L. (2012). Fast gapped-read alignment with Bowtie 2. Nature Methods, 9, 357-359. https://doi.org/10.1038/ nmeth.1923

Losos, J. B., \& Ricklefs, R. E. (2009). Adaptation and diversification on islands. Nature, 457, 830-836. https://doi.org/10.1038/nature07893

Losos, J. B., \& Schluter, D. (2000). Analysis of an evolutionary species-area relationship. Nature, 408, 847-850. https://doi.org/ 10.1038/35048558

Massatti, R., Doherty, K. D., \& Wood, T. E. (2017). Resolving neutral and deterministic contributions to genomic structure in Syntrichia ruralis (Bryophyta, Pottiaceae) informs propagule sourcing for dryland restoration. Conservation Genetics, 19, 85-97.

Massatti, R., \& Knowles, L. L. (2016). Contrasting support for alternative models of genomic variation based on microhabitat preference: Species-specific effects of climate change in alpine sedges. Molecular Ecology, 25, 3974-3986. https://doi.org/10.1111/mec.13735

Moore, W., Meyer, W. M. III, Eble, J. A., Franklin, K., Wiens, J. F., \& Brusca, R. C. (2013). Introduction to the Arizona sky island Arthropod project (ASAP): Systematics, biogeography, ecology, and population genetics of Arthropods of the Madrean sky islands. Proceedings RMRS, 2013, 144-168. 
Moritz, C. (1994). Defining Evolutionarily-Significant-Units for conservation. Trends in Ecology \& Evolution, 9, 373-375. https://doi. org/10.1016/0169-5347(94)90057-4

Nadia, T. L., \& Machado, I. C. (2014). Wind pollination and propagule formation in Rhizophora mangle L. (Rhizophoraceae): Resource or pollination limitation? Anais da Academia Brasileira de Ciências, 86, 229-238. https://doi.org/10.1590/0001-37652014101712

Nathan, R., Schurr, F. M., Spiegel, O., Steinitz, O., Trakhtenbrot, A., \& Tsoar, A. (2008). Mechanisms of long-distance seed dispersal. Trends in Ecology \& Evolution, 23, 638-647. https://doi.org/10.1016/j. tree.2008.08.003

Nettel, A., \& Dodd, R. S. (2007). Drifting propagules and receding swamps: Genetic footprints of mangrove recolonization and dispersal along tropical coasts. Evolution, 61, 958-971. https://doi. org/10.1111/j.1558-5646.2007.00070.x

Oksanen, J. F., Blanchet, G., \& Friendly, M. et al. (2017). vegan: Community ecology package. $\mathrm{R}$ package version 2.4-4.

Oliveira, E. F., Martinez, P. A., São-Pedro, V. A., Gehara, M., Burbrink, F. T., Mesquita, D. O., ... Costa, G. C. (2018). Climatic suitability, isolation by distance and river resistance explain genetic variation in a Brazilian whiptail lizard. Heredity, 120, 251-265. https://doi. org/10.1038/s41437-017-0017-2

Papadopoulou, A., \& Knowles, L. L. (2016). Toward a paradigm shift in comparative phylogeography driven by trait-based hypotheses. Proceedings of the National Academy of Sciences of the United States of America, 113, 8018-8024. https://doi.org/10.1073/pnas.1601069113

Paradis, E., Claude, J., \& Strimmer, K. (2004). ape: Analyses of phylogenetics and evolution in R language. Bioinformatics, 20, 289-290. https://doi.org/10.1093/bioinformatics/btg412

Peterson, B. K., Weber, J. N., Kay, E. H., Fisher, H. S., \& Hoekstra, H. E. (2012). Double digest RADseq: An inexpensive method for de novo SNP discovery and genotyping in model and non-model species. PLoS ONE, 7, e37135. https://doi.org/10.1371/journal.pone.0037135

Petit, R. J., Duminil, J., Fineschi, S., Hampe, A., Salvini, D., \& Vendramin, G. G. (2004). Comparative organization of chloroplast, mitochondrial and nuclear diversity in plant populations. Molecular ecology, 14, 689701. https://doi.org/10.1111/j.1365-294X.2004.02410.x

Pfeifer, B., Wittelsbürger, U., Ramos-Onsins, S. E., \& Lercher, M. J. (2014). PopGenome: An efficient Swiss army knife for population genomic analyses in R. Molecular Biology and Evolution, 31, 1929-1936. https:// doi.org/10.1093/molbev/msu136

Rabinowitz, D. (1978). Dispersal properties of mangrove propagules. Biotropica, 10, 47-57. https://doi.org/10.2307/2388105

Reaz, R., Bayzid, M. S., \& Rahman, M. S. (2014). Accurate phylogenetic tree reconstruction from quartets: A heuristic approach. PLOS ONE, 9, e104008. https://doi.org/10.1371/journal.pone.0104008

Resende-Moreira, L. C., Knowles, L. L., Thomas, A. T., Prado, J. R., Souto, A. P., Lemos-Filho, J. P., \& Lovato, M. B. (2018). Relictual Amazonian savannas: Genetic tests of past connections versus a history of isolation from central Cerrado. Journal of Biogeography, https://doi. org $/ 10.1111 /$ jbi.13468

Riddle, B. R. (2016). Comparative phylogeography clarifies the complexity and problems of continental distribution that drove A. R. Wallace to favor islands. Proceedings of the National Academy of Sciences of the United States of America, 113, 7970-7977. https://doi.org/10.1073/ pnas.1601072113

Riginos, C., Crandall, E. D., Liggins, L., Bongaerts, P., \& Treml, E. A. (2016). Navigating the currents of seascape genomics: How spatial analyses can augment population genomic studies. Current Zoology, 62, 581601. https://doi.org/10.1093/cz/zow067

Rönnbäck, P. (1999). The ecological basis for economic value of seafood production supported by mangrove ecosystems. Ecological Economics, 29, 235-252. https://doi.org/10.1016/S0921-8009(99)00016-6
Salerno, P. E., Señaris, J. C., Rojas-Runjaic, F. J. M., \& Cannatella, D. C. (2015). Recent evolutionary history of Lost World endemics: Population genetics, species delimitation, and phylogeography of sky-island treefrogs. Molecular Phylogenetics and Evolution, 82, 314323. https://doi.org/10.1016/j.ympev.2014.10.020

Simberloff, D. S., \& Wilson, E. O. (1969). Experimental zoogeography of islands: The colonization of empty islands. Ecology, 50, 278-296. https://doi.org/10.2307/1934856

Soltis, D. E., Morris, A. B., McLachlan, J. S., Manos, P. S., \& Soltis, P. S. (2006). Comparative phylogeography of unglaciated eastern North America. Molecular Ecology, 15, 4261-4293. https://doi. org/10.1111/j.1365-294X.2006.03061.x

Soltis, D. E., \& Soltis, P. S. (2017). Mobilizing and integrating big data in studies of spatial and phylogenetic patterns of biodiversity. Plant Diversity, 38, 264-270.

Stamatakis, A. (2014). RAxML version 8: A tool for phylogenetic analysis and post-analysis of large phylogenies. Bioinformatics, 30, 13121313. https://doi.org/10.1093/bioinformatics/btu033

Steele, P. R., Hertweck, K. L., Mayfield, D., McKain, M. R., LeebensMack, J., \& Pires, J. C. (2012). Quality and quantity of data recovered from massively parallel sequencing: Examples in Asparagales and Poaceae. American Journal of Botany, 99, 330-348. https://doi. org/10.3732/ajb.1100491

Straub, S. C., Fishbein, M., Livshultz, T., Foster, Z., Parks, M., Weitemier, K., ... Liston, A. (2011). Building a model: Developing genomic resources for common milkweed (Asclepias syriaca) with low coverage genome sequencing. BMC Genomics, 12, 211. https://doi. org/10.1186/1471-2164-12-211

Takayama, K., Kajita, T., Murata, J., \& Tateishi, Y. (2006). Phylogeography and genetic structure of Hibiscus tiliaceus-speciation of a pantropical plant with sea-drifted seeds. Molecular Ecology, 15, 2871-2881. https://doi.org/10.1111/j.1365-294X.2006.02963.x

Takayama, K., Tamura, M., Tateishi, Y., Webb, E. L., \& Kajita, T. (2013). Strong genetic structure over the American continents and transoceanic dispersal in the mangrove genus Rhizophora (Rhizophoraceae) revealed by broad-scale nuclear and chloroplast DNA analysis. American Journal of Botany, 100, 1191-1201. https://doi.org/10.3732/ ajb.1200567

Tomlinson, P. B. (2016). The botany of Mangroves. Cambridge, UK: Cambridge University Press. https://doi.org/10.1017/ CBO9781139946575

Walters, B. B., Rönnbäck, P., Kovacs, J. M., Crona, B., Hussain, S. A., Badola, R., ... Dahdouh-Guebas, F. (2008). Ethnobiology, socio-economics and management of mangrove forests: A review. Aquatic Botany, 89, 220-236. https://doi.org/10.1016/j.aquabot.2008.02.009

Wang, C., Szpiech, Z. A., Degnan, J. H., Jakobsson, M., Pemberton, T. J., Hardy, J. A., ... Rosenberg, N. A. (2010). Comparing spatial maps of human population genetic variation using Procrustes analysis. Statistical Applications in Genetics and Molecular Biology, 9, 13.

Wee, A. K., Takayama, K., Chua, J. L., Asakawa, T., Meenakshisundaram, S. H., Adjie, B., ... Salmo, S. G. (2015). Genetic differentiation and phylogeography of partially sympatric species complex Rhizophora mucronata Lam. and R. stylosa Griff. using SSR markers. BMC Evolutionary Biology, 15, 57. https://doi.org/10.1186/s12862-015-0331-3

Yu, G., Smith, D. K., Zhu, H., Guan, Y., \& Lam, T. T. Y. (2017). ggtree: An R package for visualization and annotation of phylogenetic trees with their covariates and other associated data. Methods in Ecology and Evolution, 8, 28-36. https://doi.org/10.1111/2041-210X.12628

Zerbino, D. R., \& Birney, E. (2008). Velvet: Algorithms for de novo short read assembly using de Bruijn graphs. Genome Research, 18, 821-829. https://doi.org/10.1101/gr.074492.107

Zhang, Q., Liu, Y., \& Sodmergen (2003). Examination of the cytoplasmic DNA in male reproductive cells to determine the potential for 
cytoplasmic inheritance in 295 Angiosperm species. Plant and Cell Physiology, 44, 941-951. https://doi.org/10.1093/pcp/pcg121

Zheng, X., Levine, D., Shen, J., Gogarten, S. M., Laurie, C., \& Weir, B. S. (2012). A high-performance computing toolset for relatedness and principal component analysis of SNP data. Bioinformatics, 28, 33263328. https://doi.org/10.1093/bioinformatics/bts606

\section{SUPPORTING INFORMATION}

Additional supporting information may be found online in the Supporting Information section at the end of the article.
How to cite this article: Hodel RGJ, Knowles LL, McDaniel SF, et al. Terrestrial species adapted to sea dispersal: Differences in propagule dispersal of two Caribbean mangroves. Mol Ecol. 2018;27:4612-4626. https://doi.org/10.1111/mec.14894 